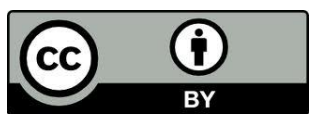

\title{
A Educação Adventista por Ellen White
}

\author{
The adventist education by Ellen White
}

Juliana Neri Munhoz Mestre em Ciências da Religião pela PUC-SP. nerimunhoz@hotmail.com

RESUMO: Neste artigo buscaremos compreender um pouco mais sobre a educação adventista proposta por Ellen White, apontando alguns elementos que serviram de base para uma boa educação na visão de Ellen White. A origem da educação adventista vem do pensamento religioso adventista e de sua orientação teológica advêm do protestantismo norte- americano do século XIX e possui influências de grupos como os anabatistas, restauracionistas e millerianos. Este estudo foi realizado para compreensão da presença de alunas e alunos não- confessionais, ou não adventistas na rede educacional adventista de Cotia- SP.

Palavras Chave: Educação; Ensino Religioso; Educação Confessional.

ABSTRACT: This article will try to understand a little more about Adventist education proposed by Ellen White, pointing out some elements that formed the basis for a good education in the vision of Ellen White. The origin of Adventist education comes from Adventist religious thought and theological orientation come from American Protestantism of the nineteenth century and has influences from groups such as the Anabaptists, restorationists, millerianos. This study was conducted to understand the presence of students and non-students denominational or non-Adventists in Adventist educational network Cotia-SP.

Keywords: Education; Religious Education; Education Confessional. 


\section{Introdução}

O Adventismo obteve um histórico ligado ao protestantismo norte- americano do século XIX e seus fundadores advinham da vertente do movimento restauracionista: Tiago White e José Bates. Ellen White, uma das mais conhecidas fundadoras do adventismo era metodista. A sua relevância aparece no percorrer do histórico do adventismo e também na formação da rede educacional adventista ( pois através de seus conselhos e instruções a respeito da educação cristã no período da década de 1870 , houve o desenvolvimento do sistema adventista de ensino com o estabelecimento de sua primeira escola em 1872).

Mostra-se relevante citar também neste artigo os estudos de Miller e a previsão da vinda de Cristo através das leituras bíblicas de Apocalipse e Daniel, pois fez parte da história da formação do grupo adventista. Miller também considerava o sábado um dia santo. Esta crença do sétimo dia talvez seja uma das doutrinas mais distintivas da igreja adventista.

\section{A educação adventista e Ellen White}

Ellen White deu uma contribuição notável para o estabelecimento de uma filosofia educacional sólida dentro das escolas adventistas. Sua filosofia educacional está nitidamente relacionada à religião. (TIMM, 2004, p. 17).

Falar em educação adventista sem falar de Ellen White seria uma forma incompleta de abordá-la: “(...) pois todo histórico do sistema educacional adventista, do seu início até a $1^{\mathrm{a}}$ década deste século, esteve atrelado aos conselhos e orientações de Ellen White, profetiza (sic) da Igreja." (MATOS, 1993, p. 58). Sua relevância aparece no percorrer do histórico educacional adventista, pois através dos conselhos e instruções a respeito da educação cristã estabelecidos por Ellen G.. White, no período da década de 1870, houve o desenvolvimento do sistema adventista de ensino com o estabelecimento de sua primeira escola em 1872. ${ }^{1}$ Pode ser considerada então pioneira no ramo educacional e também para o próprio avanço do adventismo:

Dentre todos os pioneiros, Ellen G.White é quem mais influência

\footnotetext{
${ }^{1}$ A criação da primeira escola adventista ocorre em 1872, em Michigan, nos EUA.
} 
exerce sobre os adventistas. Nascida em Gorham, no Maine, em 26 de 1827, quando era ainda menina, mudou-se para Portland com sua família, onde passou a maior parte da infância. Era uma garota alegre e prometia ter desenvolvimento intelectual acima do comum (...). (MARTINS, 2008, p. 50).

Não iremos nos deter na história de vida de Ellen White neste trabalho, porém saibamos que suas experiências quando criança foram importantes para ser considerada uma pessoa diferenciada no grupo adventista ${ }^{2}$. Ela foi tida como uma grande intelectual, pois irá escrever, tratar e expor diante da Igreja os princípios que devem reger a educação de sua juventude:

O tempo agora é demasiado curto para levar a cabo o que poderia ter sido realizado nas gerações passadas; mas podemos fazer muito, mesmo nestes últimos dias, para corrigir os males existentes na educação da juventude. E visto que o tempo é curto, devemos ser fervorosos e trabalhar zelosamente para dar aos jovens a educação compatível com a nossa fé. (WHITE, 1994, p. 28-29).

Compreendemos assim que a integração da fé e ensino se coloca no discurso pedagógico adventista elaborado por Ellen White. Para ela, a educação é o desenvolvimento harmônico das faculdades físicas, intelectuais e espirituais:

Restaurar no homem a imagem de seu Autor, levá-lo de novo à perfeição que fora criado, promover o desenvolvimento do corpo, espírito e alma para que se pudesse realizar o propósito divino de sua criação - tal deveria ser a obra da redenção. Este é o objetivo da educação, o grande objetivo da vida. (WHITE, 1996, p.15-16).

Os parâmetros e objetivos da educação, conforme colocados acima, se encontram na obra Educação, apresentada ao público em geral em 1903 por Ellen White. ${ }^{3}$ Para ela, a educação deve ter Deus no centro e ser fonte de conhecimento. A educação deve desenvolver não só os estudos, mas o ser todo, suas faculdades físicas, intelectuais e espirituais:

\footnotetext{
${ }^{2}$ Apesar de ter apenas três ou quatro anos de estudo na infância, Ellen G. White tornou-se uma grande escritora, com um estilo que é admirado até mesmo pelos críticos. Também pela superação de um acidente aos 9 anos, em que uma pedra atirada por outra colega de escola em Ellen deixou-a com o rosto deformado, não podendo respirar pelo nariz e com problemas para ler e escrever. (Martins, 2008).

${ }^{3}$ Tudo o que escreveu sobre educação, pode ser resumido a um livro em especial, de título "Educação". Nesta obra se fundamenta a filosofia educacional que norteia até hoje, com algumas adaptações, todo o sistema adventista. MATOS, 1993, p. 35.
} 
Nossas ideias acerca da educação têm sido demasiadamente acanhadas. Há a necessidade de um escopo mais amplo, de um objetivo mais elevado. A verdadeira educação significa mais do que a prossecução de um certo curso de estudos. Significa mais do que a preparação para a vida presente. Visa o ser todo, e todo período da existência possível ao homem. (WHITE, 1996, p. 14).

Para ela a educação deve conter uma influência moral e religiosa, sendo estes elementos religiosos importantes, que não devem ser deixados para trás, pois a educação tem como objetivo algo maior e deve transcender o conhecimento apenas humano:

A mais elevada educação requer algo maior, mais divino, do que o conhecimento que se obtêm meramente dos livros. Ela significa um conhecimento individual, experimental de Cristo; quer dizer emancipação de ideias, hábitos e práticas adquiridos na escola do príncipe das trevas, o que se opõem a lealdade para com Deus. (WHITE, 1994b, p. 12).

Considera-se assim que o conhecimento que exalta o humano e deixa a Palavra de Deus em segundo plano traz confusão e perversão": "Quando a palavra de Deus é posta de (sic) parte, sendo substituída por livros que desviam de Deus (...) confundem o entendimento (...) a educação é uma perversão do que se entende por esse nome." (WHITE, 1994b, p. 16). Desta forma, uma educação que não tem o cuidado com a palavra de Deus, para Ellen White seria deficiente. Por isso os educadores, conservando a palavra de Deus e seus princípios, vão incutir ideias para edificar a fé dos jovens e "ensinarão a Verdade", que é considerada a Bíblia pela autora.

Assim, a revelação bíblica deteria a posição estratégica em sistemas de conhecimento humano, pois seria a Bíblia e Deus que auxiliariam na compreensão dos diversos conhecimentos: 5 "O estudo da Bíblia é especialmente necessário nas escolas. Os alunos devem estar arraigados e fundados na verdade divina. (...) Acima de todos os outros livros, deve a Bíblia merecer nosso estudo, ela, o grande compêndio, a base de toda educação." (WHITE, 1994, p. 117).

\footnotetext{
${ }^{4}$ Nosso colégio é designado por Deus para satisfazer às necessidades deste tempo de perigo e desmoralização. (WHITE, 1994, p. 60).

${ }^{5}$ A Bíblia contém todos os princípios que os homens necessitam compreender a fim de se habilitarem tanto para esta vida como para a futura. (WHITE, 1996). Precisamos não só integrar outros tópicos no currículo com a cosmovisão bíblica, mas a aula de Bíblia deve prover discussões que podem preparar o caminho para essa integração na mente dos estudantes enfatizando a cosmovisão cristã. (KNIGHT, 2010). A Bíblia é essencial dentro da filosofia educacional adventista.
} 
Também observa que se deve dispensar atenção à preparação dos jovens para o ministério, não só proporcionar aos estudantes o mero conhecimento de livros. Assim, a educação para Ellen White deveria ser ampla e uma educação que exija de professores e diretor consideração e esforço que a mera instrução nas ciências não requer (WHITE, 1994).

Não que a "verdadeira educação", como coloca a autora, desconheça o valor dos conhecimentos científicos ou aquisições literárias; acima da instrução aprecia a capacidade, acima da capacidade a bondade, e acima das aquisições intelectuais o caráter: “(...) $\mathrm{O}$ mundo não necessita tanto de homens de grande intelecto, como de nobre caráter.” (WHITE,1996, p. 225).

O desenvolvimento do caráter é uma meta importante na educação adventista e cristã, pois "Ellen White observou que o caráter determina o destino tanto nesta vida como na do porvir." (KNIGHT, 2010, p. 113). Educação não seria então academicismo, seria o preparo para o trabalho, para a religiosidade, para a cidadania. Seria educar o intelecto, a moralidade e a religiosidade. Para Ellen White, o trabalho é estabelecido, por meio do contato manual, como o uso da terra para o cultivo e a própria educação física. Ele não é somente intelectual.

"É lei de Deus que a força, tanto para o espírito e a alma como para o corpo, se adquira por meio do esforço. É o exercício que desenvolve. De acordo com essa lei, Deus proveu em Sua Palavra os meios para o desenvolvimento mental e espiritual." (WHITE, 1996, p.22). Desta forma, a educação deve estar ligada ao cuidado com o corpo e a saúde. E para que as crianças e jovens tenham saúde, alegria, vivacidade convém que “(...) estejam muito ao ar livre, e tenham divertimentos e ocupações bem orientados. Crianças e jovens mantidos na escola e presos nos livros, não podem gozar de sã constituição física." (WHITE,1994, p. 137-138).

Momentos e atividades que exercitem o corpo fazem parte da educação proposta por Ellen White. Como descanso ao estudo, ocupações ao ar livre que proporcionem exercício ao corpo todo, são consideradas as mais benéficas para ela, como o exemplo da agricultura ${ }^{6}$ e o contato com a terra: "Nenhum ramo do trabalho manual é mais

\footnotetext{
${ }^{6} \mathrm{O}$ conjunto de mudanças educacionais proposto por Ellen White tem um de seus aspectos baseados no trabalho manual. Knight escreve que os princípios educacionais parecem imutáveis, porém sua aplicação varia através do tempo e de cultura. E completa: “(...) A agricultura é um caso em foco. (...) No século 19, a agricultura era muito relevante e útil para quase todos. A terra em muitos lugares era quase de graça $\mathrm{e}$ tudo que alguém precisava para montar um negócio era de um arado e um cavalo. (...) Entretanto, os
} 
valioso que a agricultura. (...) No estudo da agricultura, dê-se aos alunos não somente a teoria mas também a prática." (WHITE, 1994, p. 219). E mais que isso: "Insisto que em nossas escolas sejam animadas em seus esforços no sentido de formular planos para o adestramento dos jovens, na agricultura e outros ramos de trabalho industrial." (WHITE, 1994b, p. 317).

O propósito é que os alunos e alunas não tenham somente a teoria, mas também a prática. Para Ellen o jovem, ao deixar a escola, deve ter adquirido conhecimento em algum ofício ou ocupação com que, se for necessário, possa ganhar sua subsistência. ${ }^{7}$

Outros elementos educacionais são observados e fazem parte do ensino do que a escola deve proporcionar a seus alunos e alunas: como o vestuário, que, para Ellen White, mostra o caráter de uma pessoa. Os jovens teriam que perceber que a maneira singela de viver é indispensável: "A casta simplicidade no vestir, aliada à modéstia das maneiras, muito farão no sentido de cercar uma jovem com aquela atmosfera de sagrada reserva que para ela será um escudo contra os milhares de perigos." (WHITE, 1996, p. 248). A veste deveria seguir o caráter de Cristo, de forma que revelasse simplicidade e o diferencial em relação às coisas "do mundo." Característica assim do conjunto de propostas educacionais adventistas.

No conjunto de elementos necessários para haver uma boa educação, não podemos deixar de lado o que Ellen White coloca sobre como os professores devem ser para haver uma boa preparação de seus educandos: "Professores sábios devem ser escolhidos para nossas escolas, daqueles capazes de sentir diante de Deus a responsabilidade de impressionar a mente com a necessidade de conhecer a Cristo como um Salvador pessoal.” (WHITE, 1994, p. 138). A comunhão dos professores com Deus como coloca Ellen é essencial para educar a juventude, devendo não somente ter o conhecimento científico, mas serem observadores da Palavra de Deus. Pelo exemplo de vida do professor é que o educando irá aprender e "ensinará simplicidade e correção de hábitos em tudo." (WHITE, 1994).

cristãos adventistas na década de 2010 vivem em um contexto diferente.” (KNIGHT, 2010, p. 236). Knight se refere à tecnologia, que hoje exige a adaptação da educação a esta realidade.

${ }^{7}$ Tais propostos são encontrados também no livro de Pedagogia Adventista de 2010, dentro de seus objetivos, como o "incentivo ao desenvolvimento dos deveres práticos da vida diária, a sábia escolha profissional e a formação familiar, a serviço de Deus e da comunidade.” (p. 51). Como o trabalho manual útil colocado por Ellen White. 
Desta forma, Ellen considera que os professores serão colaboradores de Deus e saberão como ensinar, que lições comunicar e estudar sobre as "lições de Cristo". As qualificações dos professores advêm tanto da competência escolar quanto do cristianismo experiencial. (KNIGHT, 2010).

Ellen White coloca que a tarefa dos professores seria despertar assim esperança e aspirações nos jovens, "moldando o caráter destes em harmonia com Deus." Deve preservar então a paciência, a bondade, a misericórdia e o amor. ${ }^{8}$

A educação para ela seria um conhecimento experimental no plano da Salvação, os estudantes devem ser ensinados pelos seus professores que estão no mundo para prestarem serviço a Deus. Podemos perceber um dos momentos de estudos religiosos nas "aulas de Bíblia". Esta parte do currículo proposto para os estudos religiosos são também escritos por Ellen White e propõe doutrinas, fatos bíblicos, descobertas arqueológicas, correlações do pensamento bíblico com a filosofia grega, as implicações dos distintos pontos de linguagem. (KNIGHT, 2010).

Ellen White fez um apelo aos professores: "Imploro que temeis a Deus como vosso conselheiro. Não sois responsáveis perante homem algum, mas estais sob a direção de Deus. Mantende-vos junto dEle (sic). Não tomeis ideias mundanas como vosso critério. Não vos afasteis dos métodos de trabalho do Senhor." (WHITE, 1994, p. 219). Assim, o professor ou professora adventista têm que ser qualificados e ter experiência cristã, o que exige maior dedicação e esforço nos estudos e ensino bíblico. Este ensino se aplica nas escolas adventistas por intermédio das aulas de Ensino Religioso.

Ellen White considerava que o aprendizado da criança e do jovem envolve o exemplo deste professor ou professora, em especial o de Ensino Religioso, que trabalha com "lições bíblicas". Sendo assim, aquilo que é ensinado deve ser também vivenciado pelo mestre, senão revela contrastes e não tem efeito sobre a criança ou o jovem: “(...) tais são lições que apenas aquele que as aprendeu por si mesmo poderá ensinar. $\mathrm{O}$ fato de que o ensino das Escrituras não tem maior efeito sobre a juventude, é devido a que tantos pais e mestres professem crer na Palavra de Deus, enquanto sua vida nega o

\footnotetext{
${ }^{8}$ No livro Pedagogia Adventista (2010), encontramos que a importância do professor se dá quando forma, modela e aprimora caracteres. A liderança espiritual, o conhecimento técnico de sua área, visão estratégica, equilíbrio emocional são elementos que fazem parte do conjunto do profissional adventista devidamente qualificado.
} 
poder dela." (WHITE, 1996, p. 259). A Bíblia é pela autora considerada instrumento de instrução moral, e se aqueles que professam crer nela não lhe derem seu devido valor, estão rejeitando-a: “(...) E esta rejeição por parte dos que professam crer nela, é a causa preeminente do ceticismo e incredulidade entre os jovens." (WHITE,1996, p.262).

O professor ou professora, ao lidarem com estes jovens ou crianças na escola adventista, podem encontrar alguns problemas pela falta de vivência religiosa no seu cotidiano. $^{9}$ Ao trabalharem com os alunos e alunas que por ventura sejam incrédulos, indisciplinados, devem lembrar-se que “(...) ao tratar com eles nunca deve esquecer-se de que ele mesmo foi criança, necessitando de disciplina.(...) a regra do Salvador como vós quereis que os homens vos façam, da mesma maneira lhes fazei vós também (S. Luc. 6:31) - deve ser a regra de todos os que empreendem a educação das crianças e jovens.”(WHITE, 1996, p. 292). Então, ao trabalhar com a dificuldade dos alunos e alunas: "Ensine-se à criança e jovem que todo erro, toda falta, toda dificuldade vencidos, se tornam um degrau no acesso a coisas melhores e mais elevadas." (WHITE, 1996, p. 296).

\section{Referenciais}

KNIGHT, George R. A visão apocalíptica e a neutralização do adventismo. Casa Publicadora Brasileira, Tatuí- São Paulo, 2010.

KNIGHT, George R. Em busca de identidade. O desenvolvimento das doutrinas adventistas do sétimo dia. Ed. Casa Publicadora Brasileira. Tatuí- São Paulo, 2011.

MAINWARING, Scott. A Igreja Católica e a Política no Brasil. Ed. Brasiliense, 1989.

MARTINS, Enilce Barbosa. Educação como obra missionária: a educação como instrumento de difusão da filosofia adventista. Tese de Mestrado em Ciências da Religião- PUC -SP, 2008.

MATOS, Josmar Sionti Arrais. Memória e História do trabalho missionário adventista no Brasil. Tese de mestrado em História na PUC- SP, São Paulo,1993.

MAXUELL, C.Mervyn. História do Adventismo. Casa Publicadora Brasileira, Santo André- São Paulo, $1^{\mathrm{a}}$ edição.1982.

\footnotetext{
${ }^{9}$ Dentro dos princípios metodológicos da proposta educacional adventista do Colégio Adventista de Cotia - 2010, encontramos que: "O ensino se torna eficaz na medida em que o docente é capaz de estabelecer a integração entre o conteúdo e os valores por ele defendidos e vividos.” (PROJETO PEDAGÓGICO, 2010, p. 8).
} 


\section{SITES:}

MENSLIN, Douglas Jeferson. Perfil do professor de Ensino Religioso nos anos iniciais do ensino fundamental da rede educacional adventista no sul do Brasil. Tese de Mestrado- PUC PR, 2009. Disponível no site: http://www.gper.com.br/documentos/pos_graduacao/dissertacao_douglas_menslin.pdf Acesso dia 01/06/2012.

SANTOS, Ivanaldo. O tomismo militante: o discurso- ação de Plinio Corrêa de Oliveira. Artigo publicado na Revista Eletrônica de Estudos Tomistas Aquinate, n.9, 2009. Disponível no site: http://www.revolucaocontrarevolucao.com/verartigo.asp?id=182 Acesso dia 12/01/2012.

KNIGHT, George. Os alvos da educação adventista: uma perspectiva histórica. Revista de educação adventista. Número 13 de 2001. Disponível no site: http://circle.adventist.org//files/jae/po/jae2001po130506.pdf Acesso dia 29/9/2011.

SILVA, Marcos. A penetração adventista no Brasil. Site da HISTEDBR- Navegando na história da educação brasileira. 20 de julho de 2011. http://www.histedbr.fae.unicamp.br/navegando/artigos_pdf/Marcos_Silva_Artigo.pdf

Recebido: 05/03/2013

Received: 03/05/2013

Aprovado: 04/07/2013

Approved: 07/04/2013 